\title{
The Burden of Cardiovascular Disease Attributable to Major Modifiable Risk Factors in Indonesia
}

\author{
Mohammad Akhtar Hussain ${ }^{1}$, Abdullah Al Mamun ${ }^{1}$, Sanne AE Peters ${ }^{2}$, \\ Mark Woodward ${ }^{2,3}$, and Rachel R. Huxley ${ }^{4}$ \\ ${ }^{1}$ Division of Epidemiology and Biostatistics, School of Public Health, The University of Queensland, Brisbane, Australia \\ ${ }^{2}$ The George Institute for Global Health, Nuffield Department of Population Heath, University of Oxford, Oxford, United Kingdom \\ ${ }^{3}$ The George Institute for Global Health, The University of Sydney, Sydney, Australia \\ ${ }^{4}$ School of Public Health, Curtin University, Perth, Australia
}

Received June 29, 2015; accepted November 11, 2015; released online March 26, 2016

Copyright $@ 2016$ Mohammad Akhtar Hussain et al. This is an open access article distributed under the terms of Creative Commons Attribution License, which permits unrestricted use, distribution, and reproduction in any medium, provided the original author and source are credited.

\begin{abstract}
Background: In Indonesia, coronary heart disease (CHD) and stroke are estimated to cause more than 470000 deaths annually. In order to inform primary prevention policies, we estimated the sex- and age-specific burden of CHD and stroke attributable to five major and modifiable vascular risk factors: cigarette smoking, hypertension, diabetes, elevated total cholesterol, and excess body weight.

Methods: Population attributable risks for CHD and stroke attributable to these risk factors individually were calculated using summary statistics obtained for prevalence of each risk factor specific to sex and to two age categories ( $<55$ and $\geq 55$ years) from a national survey in Indonesia. Age- and sex-specific relative risks for CHD and stroke associated with each of the five risk factors were derived from prospective data from the Asia-Pacific region. Results: Hypertension was the leading vascular risk factor, explaining $20 \%-25 \%$ of all CHD and $36 \%-42 \%$ of all strokes in both sexes and approximately one-third of all CHD and half of all strokes across younger and older age groups alike. Smoking in men explained a substantial proportion of vascular events ( $25 \%$ of CHD and $17 \%$ of strokes). However, given that these risk factors are likely to be strongly correlated, these population attributable risk proportions are likely to be overestimates and require verification from future studies that are able to take into account correlation between risk factors.

Conclusions: Implementation of effective population-based prevention strategies aimed at reducing levels of major cardiovascular risk factors, especially blood pressure, total cholesterol, and smoking prevalence among men, could reduce the growing burden of CVD in the Indonesian population.
\end{abstract}

Key words: population attributable risk; risk factors; attributable risk; non-communicable diseases; cardiovascular diseases

\section{INTRODUCTION}

Indonesia is the fourth most populous country in the world, with a population of 250 million people, and has experienced rapid economic growth over the past couple of decades. ${ }^{1}$ With improved health financing, increased social mobilization, community empowerment, and prioritization of primary health care, the country has made visible achievements in several health outcomes. For example, life expectancies have steadily increased from 62 to 69 and 65 to 73 years for men and women, respectively, over the past decades, and rates of infant and maternal mortality have significantly decreased, in line with the Millennium Developmental Goals. ${ }^{1}$
As a likely consequence of improvements in the country's economic development, Indonesia is experiencing a rapid epidemiological transition in terms of both its current and projected disease burden. While the existing burden of communicable diseases - and the likelihood of emerging diseases with epidemic or pandemic potential—is a key concern in Indonesia, the burden of disease related to noncommunicable diseases has become a major public health issue. $^{2-5}$ Roughly a third of all deaths in Indonesia are attributable to cardiovascular disease (CVD), with stroke and coronary heart disease (CHD) being the leading causes of mortality in the country. $3,5-8$ 
Similar to the situation in most other lower- and middleincome countries in the Asia-Pacific region, the prevalence of major cardiovascular risk factors, including excess body weight, diabetes, and elevated blood pressure, has risen in the Indonesian population. ${ }^{9-17}$ However, previous prevalence estimates were largely derived from demographic surveillance sites that were not nationally representative ${ }^{9-11}$ or were "guestimates" from modelling studies. ${ }^{14-17}$ The importance of obtaining reliable estimates of the prevalence of major and modifiable vascular risk factors cannot be overstated, as such data are the cornerstone of effective primary CVD prevention programs. Thus, we aimed to obtain representative prevalence estimates of cardiovascular risk factors as well as burden of CVD attributable to these risk factors using more reliable data sources than were used in previous studies.

\section{METHODS}

\section{Risk factor assessment}

The prevalence estimates included in this analysis were derived from a published report of Riskesdas 2013, a nationally representative survey conducted by the Republic of Indonesia's Ministry of Health in 2013. ${ }^{18}$ The details about survey methodology, ethical clearance, data collection, validation, and analysis are explained in detail in the Riskesdas report 2013. ${ }^{18}$ Briefly, the survey included 1027763 subjects (approximately 300000 households) at all ages from 33 districts of the country sampled through a probabilistic multi-stage process (eFigure 1). The Riskesdas households were selected based on the Population Census listing of 2010. The household selection process was determined by the Indonesian Central Bureau of Statistics, which provided a list of selected census buildings from selected census blocks using the technique of probability proportional to size (PPS). From each selected census block, 25 households were randomly selected, and from each selected household, all household members were considered as individual samples. The ethical clearance for the survey implementation was given by the Indonesian Ministry of Health's National Institute of Health Research and Development Health Research Ethics Committee (IEC) (http://www.litbang.depkes.go.id/komisi-etik). For our analysis, we included information from subjects aged $\geq 15$ years $(n=722330)$. For collection of biomedical samples, a sub-sample of 1000 census blocks was randomly selected, and all household members of 25 selected households (approx. family size: 3.8) from each census block were included. Random blood samples were obtained from 40250 participants aged $\geq 15$ years who provided informed consent. Of these, values for fasting blood glucose and serum total cholesterol were available for $38136(94.7 \%)$ and 35609 $(88.4 \%)$ individuals, respectively. The age and sex distributions of participants in Riskesdas 2013 are presented in supplementary eTable 1 . Of the 300000 households targeted for the survey, $98.3 \%$ were successfully visited, giving an individual participant response rate of $93.0 \%$ (eTable 2).

Exposure status for each of the five risk factors was ascertained from either participants' self-reports given in the standardized interview or measurements performed using standardized and quality-controlled procedures by trained personnel at the baseline examination. ${ }^{18}$ Smoking status (defined as occasionally/regularly or not) was based on self-report and was obtained from all participants aged $\geq 15$ years. Blood pressure measurements $(n=661367)$ were obtained only in those aged $\geq 18$ years using a digital sphygmomanometer (Omron IA2; Omron, Kyoto, Japan). Hypertension was defined as systolic blood pressure $\geq 140 \mathrm{~mm} \mathrm{Hg}$ or a diastolic blood pressure $\geq 90 \mathrm{~mm} \mathrm{Hg}$ (Joint National Committee on Prevention, Detection, Evaluation, and Treatment of High Blood Pressure VII criteria). ${ }^{19}$ Diabetes was ascertained based on a self-report of a previous diagnosis of diabetes or use of anti-diabetic medication; presence of classic symptoms of hyperglycemia (polyuria, polydipsia, polyphagia, or unexplained weight loss) and a random plasma glucose $\geq 200 \mathrm{mg} / \mathrm{dL}(11.1 \mathrm{mmol} / \mathrm{L})$; by fasting plasma glucose $\geq 126 \mathrm{mg} / \mathrm{dL}$ ( $7 \mathrm{mmol} / \mathrm{L})$; or by $2-\mathrm{h}$ serum glucose concentration $\geq 200 \mathrm{mg} / \mathrm{dL}$ after an oral glucose challenge. ${ }^{20,21}$ Elevated total cholesterol was conservatively defined as total cholesterol $\geq 5.2 \mathrm{mmol} / \mathrm{L}(200 \mathrm{mg} / \mathrm{dL})$ rather than the more standard cut-point of $6.2 \mathrm{mmol} / \mathrm{L}$, to include borderline high cholesterol individuals as well. ${ }^{22}$ Height was measured using an aluminium stadiometer capable of measuring to $0.1 \mathrm{~cm}$, and weight was measured using a digital weighing machine measuring to the nearest $0.1 \mathrm{~kg}$ (Fesco, Jakarta, Indonesia). Excess body weight was defined in adults $\geq 18$ years $(n=649625)$ as a body mass index (BMI) value $\geq 25 \mathrm{~kg} / \mathrm{m}^{2}$. The reported categorical values for the sexspecific prevalence for each of the cardiovascular risk factors were extracted from the survey report. ${ }^{18}$ The age-adjusted prevalence was calculated separately for younger $(<55$ years) and older ( $\geq 55$ years) individuals. This age stratification was restricted according to the availability of risk estimates for these age groups.

\section{Relative risks of CHD and stroke}

We obtained estimates of the relative risks (RRs) and their 95\% confidence intervals (CIs) for CHD (fatal and non-fatal) and stroke (fatal and non-fatal) and by major stroke subtype (ischaemic and haemorrhagic) attributable to each of the five cardiovascular risk factors using Asian data from the Asia Pacific Cohort Studies Collaboration (APCSC). ${ }^{23}$ RRs for fatal events were also calculated. The definitions used for the risk factor exposures (eg, hypercholesterolemia $\geq 5.2 \mathrm{mmol} / \mathrm{L}$ ) corresponded to the definitions used in Riskesdas 2013. The age- and sex-specific RRs were calculated using Cox proportional hazard models, which were adjusted for age and sex and stratified by study. 


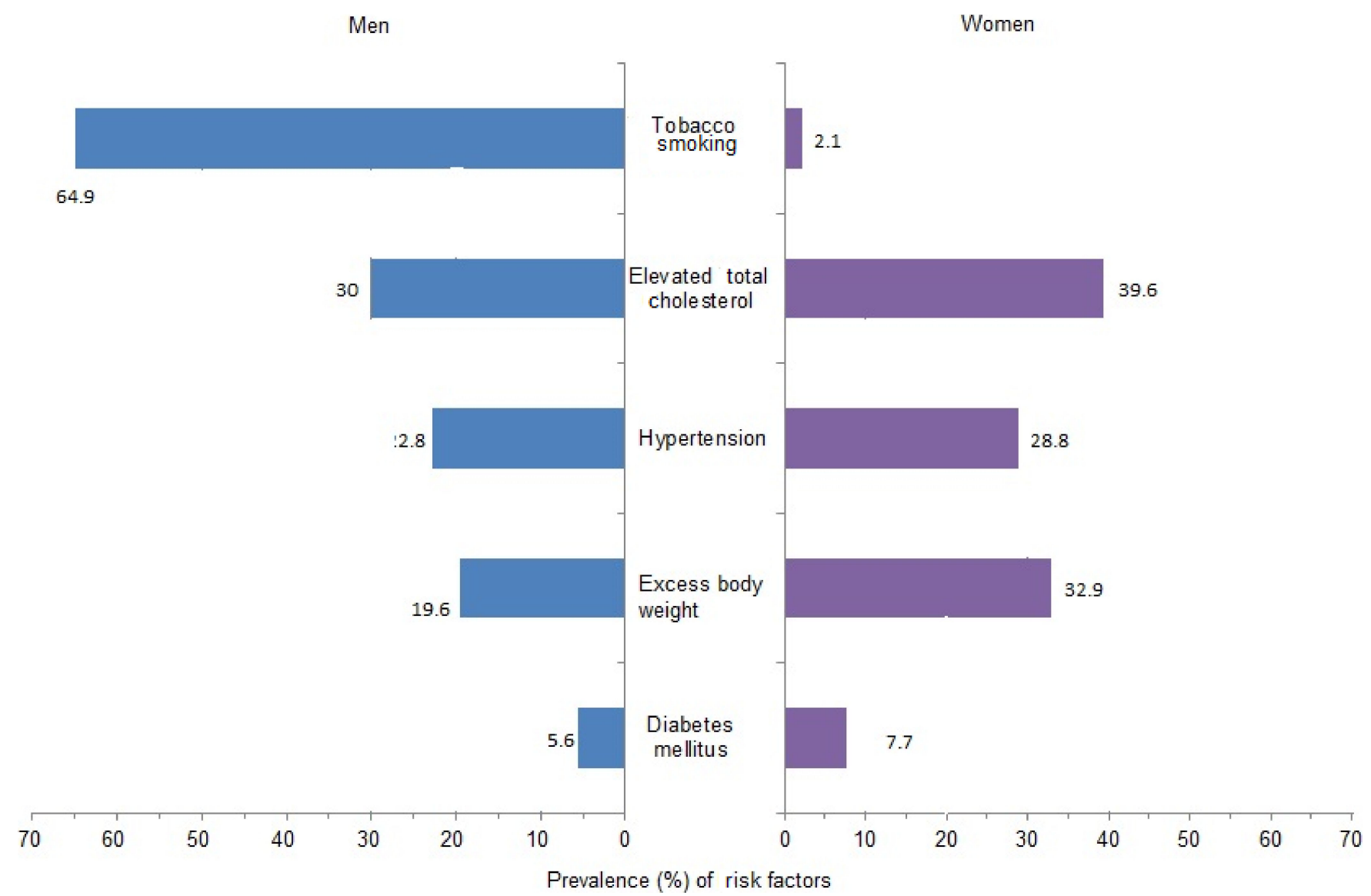

Figure 1. Prevalence (percentages) of selected cardiovascular risk factors in the Indonesian population. Prevalence of hypertension and overweight $\left(\mathrm{BMl} \geq 25 \mathrm{~kg} / \mathrm{m}^{2}\right)$ was measured in individuals $\geq 18$ years of age. Diabetes, smoking, and elevated total cholesterol (total serum cholesterol $\geq 5.2 \mathrm{mmol} / \mathrm{L}$ ) were estimated for individuals $\geq 15$ years old.

\section{Statistical analysis}

The Levin formula (equation 1) for the population attributable risk proportion (PAR) for dichotomous exposures was used to obtain an estimate of the proportion of cases of CHD and stroke in the Indonesian population that can be attributed to exposure to a given cardiovascular risk factor. ${ }^{24}$

$$
\mathrm{PAR}=\left[\mathrm{P}_{e}(\mathrm{RR}-1)\right] /\left[\mathrm{P}_{\mathrm{e}}(\mathrm{RR}-1)+1\right]
$$

where $\mathrm{P}_{e}$ is prevalence of an individual risk factor in the Indonesian general population and $\mathrm{RR}$ is age- and sexadjusted and study-stratified RR.

We used the substitution method to calculate 95\% CIs for PARs, which assumes that variability in the prevalence estimation is negligible compared to variability in the RR estimates. $^{25}$ The standard errors of the RRs were extracted from the log-transformed $95 \%$ CIs available for each RR. Monte Carlo simulation ${ }^{26}$ of 10000 iterations for each risk factor and for each sex and age category, from which we determined the 2.5 and 97.5 percentiles as empirical confidence limits for PAR, was performed using the Ersatz bootstrap add-in for Microsoft Excel (EpiGear, Sunrise Beach, Australia). ${ }^{27}$

\section{RESULTS}

Of the risk factors included in this analysis, cigarette smoking was the most prevalent risk factor in men (64.9\%), followed by elevated total cholesterol, hypertension, excess bodyweight, and diabetes (Figure 1). In women, the prevalence of smoking was low $(2.1 \%)$, and elevated total cholesterol was the most prevalent risk factor (39.6\%), followed by excess body weight, hypertension, and diabetes. The frequencies of all five risk factors differed significantly between men and women (all $P<0.001$ ). Smoking and overweight were more common in younger $(<55$ years) than older ( $\geq 55$ years) individuals (eFigure 2). By comparison, hypertension, diabetes, and high total cholesterol were more prevalent in older than younger individuals.

The PARs of CHD and stroke due to five major vascular risk factors in men and women are shown in Table 1. The percentage of $\mathrm{CHD}$ in men attributable to the risk factors ranged from $4.2 \%$ to $25.1 \%$, with the greatest attributable fraction due to smoking and then hypertension (19.7\%). In women, PARs ranged from $1.4 \%$ to $25.3 \%$, with the highest attributable fraction due to hypertension and the lowest to smoking. Elevated total cholesterol also accounted for a large 
Table 1. Age- and sex-specific PAR percentages (95\% Cls) associated with selected cardiovascular risk factors for incident CHD and stroke and its major subtypes in Indonesia

\begin{tabular}{|c|c|c|c|c|}
\hline & \multicolumn{2}{|c|}{ Sex } & \multicolumn{2}{|c|}{ Age group } \\
\hline & Men & Women & $<55$ years & $\geq 55$ years \\
\hline \multicolumn{5}{|l|}{ All CHD } \\
\hline Smoking & $25.1(16.3,32.8)$ & $1.4(0.7,2.3)$ & $20.3(13.2,27.9)$ & $10.6(5.0,15.7)$ \\
\hline Hypertension & $19.7(16.3,23.6)$ & $25.3(18.1,32.6)$ & $32.9(28.7,37.5)$ & $33.1(26.6,39.0)$ \\
\hline Elevated total cholesterol & $19.0(14.2,23.9)$ & $17.8(7.2,27.3)$ & $25.3(20.0,31.6)$ & $17.7(8.5,25.7)$ \\
\hline Excess body weight & $9.4(6.0,12.7)$ & $10.4(2.2,19.2)$ & $19.6(14.1,25.1)$ & $3.3(-0.3,7.9)$ \\
\hline Diabetes & $4.2(2.3,6.3)$ & $10.7(5.1,17.6)$ & $7.9(5.3,11.0)$ & $8.4(3.9,13.8)$ \\
\hline \multicolumn{5}{|l|}{ All stroke } \\
\hline Smoking & $16.7(11.7,21.8)$ & $0.6(0.2,1.0)$ & $11.1(6.2,15.4)$ & $3.7(0.5,6.7)$ \\
\hline Hypertension & $37.2(34.8,39.6)$ & $38.9(34.7,42.9)$ & $49.0(46.5,51.6)$ & $52.9(49.6,56.3)$ \\
\hline Elevated total cholesterol & $3.9(1.1,7.0)$ & $6.9(1.3,12.5)$ & $10.3(7.0,13.7)$ & $2.2(-3.7,7.5)$ \\
\hline Excess body weight & $5.4(3.2,7.4)$ & $8.2(3.4,12.5)$ & $14.6(11.1,17.9)$ & $0.4(-1.8,2.8)$ \\
\hline Diabetes & $3.8(2.6,5.0)$ & $7.1(3.9,10.5)$ & $6.3(4.8,7.9)$ & $5.8(2.8,8.8)$ \\
\hline \multicolumn{5}{|l|}{ Ischaemic stroke } \\
\hline Smoking & $25.1(16.6,33.3)$ & $0.6(0.1,1.3)$ & $14.4(6.8,23.1)$ & $7.1(2.1,12.6)$ \\
\hline Hypertension & $29.3(25.1,33.0)$ & $37.3(30.8,43.9)$ & $38.2(33.5,43.4)$ & $53.2(47.6,58.3)$ \\
\hline Elevated total cholesterol & $10.1(5.6,15.0)$ & $10.1(0.4,19.9)$ & $19.3(13.6,24.9)$ & $2.6(-5.4,11.6)$ \\
\hline Excess body weight & $10.6(7.2,14.2)$ & $15.1(7.7,22.2)$ & $22.7(17.4,28.6)$ & $4.4(0.9,8.1)$ \\
\hline Diabetes & $5.3(3.6,7.6)$ & $6.0(1.2,12.7)$ & $8.3(5.7,11.3)$ & $7.3(2.6,12.7)$ \\
\hline \multicolumn{5}{|l|}{ Haemorrhagic stroke } \\
\hline Smoking & $10.6(1.2,19.6)$ & $0.6(0.1,1.4)$ & $4.4(-2.9,10.9)$ & $3.3(-1.7,8.8)$ \\
\hline Hypertension & $47.3(43.1,51.3)$ & $46.6(39.7,53.2)$ & $61.3(57.1,65.2)$ & $56.2(50.8,61.6)$ \\
\hline Elevated total cholesterol & $-2.6(-7.5,2.3)$ & $5.7(-5.0,16.2)$ & $1.1(-4.2,6.6)$ & $2.8(-7.5,12.9)$ \\
\hline Excess body weight & $3.8(0.7,7.6)$ & $1.9(-5.4,9.6)$ & $10.9(5.1,16.8)$ & $-1.2(-5.0,3.1)$ \\
\hline Diabetes & $2.3(0.5,4.3)$ & $8.4(2.0,17.1)$ & $4.9(2.5,7.8)$ & $2.7(-2.6,9.7)$ \\
\hline
\end{tabular}

$\mathrm{CHD}$, coronary heart disease; $\mathrm{Cl}$, confidence interval; PAR, population attributable risk.

CHD burden in both sexes, accounting for $19 \%(95 \% \mathrm{CI}$, $14.2 \%-23.9 \%)$ of CHD events in men and $17.8 \%(95 \% \mathrm{CI}$, $7.2 \%-27.3 \%)$ in women. Similar results were also found for analyses involving only fatal CHD (eTable 3).

When comparing older versus younger individuals (men and women combined), hypertension conferred the highest PAR in both age groups (Table 1) and accounted for approximately $33 \%$ of all CHD in both age groups.

For stroke, hypertension was the leading risk factor in both sexes, accounting for $37.2 \%$ of stroke episodes in men and $38.9 \%$ of strokes in women (Table 1). When distinguishing between stroke subtypes, notable differences in the attributable fraction were observed: roughly half of all haemorrhagic strokes in women and men, and in younger and older individuals, were attributable to hypertension (Table 1). For ischemic stroke, hypertension explained about one-third of all events in women and men and in those aged $<55$ years, while it accounted for more than half of all ischemic strokes in those aged $\geq 55$ years. Smoking explained $16 \%$ of all strokes in men and $0.6 \%$ of strokes in women. Elevated total cholesterol accounted for approximately $10 \%$ of all ischemic strokes in both sexes (and was unrelated to haemorrhagic stroke). The attributable burden of ischemic stroke due to elevated total cholesterol, excess body weight, and smoking was higher in younger versus older individuals (eTable 2). The results were highly comparable for fatal strokes (eTable 3).

\section{DISCUSSION}

Contemporary estimates indicate that CHD and stroke are already the leading causes of death in the Indonesian population, accounting for more than $30 \%$ ( 0.47 million) of all mortality. ${ }^{8}$ Findings from the current study suggest that a substantial amount of the burden of CHD and stroke in the Indonesian population is attributable to major and modifiable (and therefore, preventable) vascular risk factors, most notably elevated blood pressure, total cholesterol, and cigarette smoking (but only in men). However, we observed some notable disparities in the vascular burden due to specific risk factors, as well as important sex and age differences. For example, in men, hypertension was the leading risk factor, attributing to $35 \%-40 \%$ of all stroke and $20 \%$ of all CHD, followed by smoking, which accounts for a quarter of all CHD and $16 \%$ of all stroke. However, in women, hypertension alone was the dominant risk factor, accounting for $25 \%$ of all CHD and $39 \%$ of all stroke events, while each of the remaining risk factors explained between $2 \%$ and $20 \%$ of the vascular burden. Across both younger and older age groups, hypertension was the single leading risk factor, accounting for $33 \%$ of all $\mathrm{CHD}$ and $50 \%$ of all stroke episodes. In comparison, smoking, high cholesterol, and excess body weight were responsible for a higher vascular burden in younger compared with older individuals. 
A key strength of the current study was that it used nationally representative data from the Riskesdas 2013 survey to obtain age- and sex-specific estimates of the prevalence of these major and modifiable vascular risk factors in the Indonesian adult population. In men, smoking was the most prevalent risk factor; approximately two-thirds of men were current smokers compared with only $2 \%$ of women, which wholly explains the dominance of smoking in the PAF estimates observed in men. This sex-disparity in smoking rates is a common pattern in most lower- and middle-income countries in the Asia-Pacific region, especially in neighbouring countries like Malaysia and the Philippines. ${ }^{28,29}$ By comparison, elevated cholesterol and excess body weight were more prevalent in women compared to men; this greater prevalence of excess body weight explains the greater proportion of vascular events in women than in men. Although the prevalence of diabetes was similar between the sexes (5.6\% in men and $7.7 \%$ in women), diabetes explained nearly twice the number of all CHD and strokes in women than in men due to the relationship between diabetes with vascular outcomes being significantly stronger in women than in men. ${ }^{30,31}$

In general, our results are in agreement with previous findings. ${ }^{3,32-36}$ For example, high blood pressure, tobacco smoking, high BMI, and high total cholesterol were among the major risk factors for vascular disease in Indonesia identified by the Global Burden of Disease 2010 report, ${ }^{3}$ the estimates from which were largely based on data from the 2001 STEPS survey and additional small, non-representative surveys. ${ }^{9,14,16,37-39}$ In comparison, in the current study, we used the age- and sex-specific prevalence estimates for risk factors extracted from the latest round of the basic health research Riskesdas 2013 survey. However, the lack of prospective cohort studies specific to the Indonesian population meant that relative risk estimates were sourced from the APCSC. Nonetheless, this is likely to have afforded more reliable estimates of the relationships of each of the risk factors with vascular outcomes in the Indonesian population than if we had used relative risk estimates derived from non-Asian studies. ${ }^{23,40}$ The dominance of hypertension as the preeminent vascular risk factor in the Indonesian adult population is consistent with previous reports from large-scale initiatives, including the APCSC $^{41}$ and INTERHEART. ${ }^{33}$ Ezzati et al previously reported that $45 \%$ of global CHD is attributable to hypertension, which is double the proportion that we observed in the current study. ${ }^{36}$ This discrepancy is likely due to the use of $115 \mathrm{~mm} \mathrm{Hg}$ as the lower threshold for blood pressure used for risk estimation in that study compared to the much more conservative definition of hypertension used in Riskesdas 2013 (140/90 mm Hg). Moreover, in the current study, individuals taking antihypertensive medication were not included in the definition of hypertension, nor were individuals with 'pre-hypertension' (ie, systolic blood pressure between $120-139 \mathrm{~mm} \mathrm{Hg}$ ), which would have necessarily resulted in an underestimation of the true burden of elevated blood pressure on vascular disease.

The study has several limitations. First, the five risk factors included in the model were limited to those that were reported in Riskesdas 2013 and for which we could obtain estimates of effect from the APCSC database; consequently, we did not examine the contribution of other established risk factors, such as diet and physical activity, to the burden of vascular disease. Second, the prevalence of risk factors was reported according to pre-defined categories, and we did not have access to the individual-level data that would have facilitated the derivation of standard errors around the prevalence estimates, which would have allowed the calculation of the PARs for CHD and stroke attributable to all five risk factors combined or within specific sex-age groups. However, we estimated the posterior probability of PAR estimates for individual risk factors through Monte Carlo simulation (10000 iterations) using the substitution method ${ }^{25}$ (assuming that the variability in prevalence estimates is minimal compared to that of the relative risk). Related to this limitation, we were unable to take into account possible correlation between the five risk factors, as we did not have access to individual-level data. Consequently, contained within the PAR estimates was the implicit assumption that the five risk factors acted independently to increase vascular risk, which is highly unlikely. For example, BMI is known to have both direct and indirect effects on vascular risk (the latter being partly driven by the impact of BMI on risk of diabetes). Hence, the PAR estimates that we present do not take into consideration either the clustering or the non-independence of risk factors, so they are likely to be overestimates. Alternate case-based estimation methods would be more appropriate in this situation, as such methods utilize the adjusted attributable fraction derived from the relative risk and prevalence of exposure among the diseased and produce internally valid estimates when confounding exists. ${ }^{42,43}$ Additional alternatives, such as the stratification-based adjustment method, sequential attributable fraction, and regression model-based approaches, would have been useful for dealing with multiple risk factors that have direct and indirect effects on the exposure-effect association. $^{44,45}$ However, as we did not have individuallevel data, we were unable to apply any of these alternate, and more appropriate, methods for estimation of the PAFs. Future studies should be carried out using individual-level data, which will enable the modelling of relationships between risk factors and the outcome and allow calculation of flexible and efficient estimation of the adjusted PAF, taking into account several categorical or continuous risk factors or confounding factors with or without their interactions and allowing for the analysis of potential effect modification. ${ }^{45}$

Recently, the Indonesian government has operationalized several initiatives to combat the growing cardiovascular epidemic, including training primary care workers and family practitioners to assess and manage cardiovascular 
risk, enacting legislation for pictorial warnings to cover a significant area $(40 \%)$ on tobacco product packages, ${ }^{46}$ developing of non-smoking areas, and empowering communities to control risk factors for cardiovascular disease through the establishment of 'Integrated Health Training Posts (Posbindu) in NCD'. Whether these and other measures ${ }^{2}$ will be effective in reducing Indonesia's cardiovascular burden will depend, in part, on the coverage of the interventions across the Indonesian archipelago, whether the policies are enforced, and the cultural acceptability of the interventions across all population sub-groups.

In summary, although our findings are likely to have overestimated the vascular disease burden due to five major and modifiable risk factors, they support the viewpoint that a substantial proportion of premature cardiovascular morbidity and mortality in the Indonesian population is preventable. Indonesia already has a high unmet need for cardiovascular care $^{47}$; the present analysis provides useful and timely information that could be used for the identification and prioritization of public health interventions for the primary prevention of vascular disease in the overall Indonesian population and within specific subgroups. Ultimately, primary prevention strategies that focus on lowering mean levels of blood pressure at the population level and reducing the prevalence of smoking in men are likely to have a profound impact on reducing the burden of vascular disease in the Indonesian population.

\section{ONLINE ONLY MATERIALS}

eTable 1. Distribution of Riskesdas sample (age $\geq 15$ years) by age and sex compared with the national census population. eTable 2. Distribution of census blocks, households, and individual household member and their response rates in different provinces of Indonesia, 2013.

eTable 3. Sex- and age-specific PAR (\%) associated with selected cardiovascular risk factors for fatal CHD and stroke in the Indonesian population.

eFigure 1. Sampling strategy used for selection of households and individual participants in the Riskesdas survey.

eFigure 2. Age-standardized prevalence (\%) of selected cardiovascular risk factors in the Riskesdas survey.

\section{ACKNOWLEDGEMENTS}

Dr. Woodward reported receiving funding from Roche, Novartis, Amgen and Sanofi.

\section{REFERENCES}

1. World Bank. Indonesia Economic Quarterly, December 2014: Delivering Change. Washington, DC: The World Bank; 2014.

2. Ministry of Health Republic of Indonesia. Indonesia Health Profile 2013. Jakarta, Indonesia 2014.
3. Global burden disease profiles: Indonesia Seattle, WA, USA: Institute of Health Metrics and Evaluation; 2013 [cited 2014 19 July]. Available from: http://www.healthdata.org/sites/ default/files/files/country_profiles/GBD/ihme_gbd_country_report indonesia.pdf.

4. World Bank. Indonesia: facing up to the double burden of malnutrition. Indonesia Health Sector Review: policy and discussion note. Washinton, DC: World Bank; 2012.

5. World Health Organization. Noncommunicable Diseases (NCD) Country Profiles, 201420144 March 2015 [cited 20154 March]. Available from: http://www.who.int/nmh/countries/ idn_en.pdf?ua=1.

6. Hoy DG, Rao C, Hoa NP, Suhardi S, Lwin AM. Stroke mortality variations in South-East Asia: empirical evidence from the field. Int J Stroke. 2013;8 Suppl A100: 21-7.

7. Kusuma Y, Venketasubramanian N, Kiemas LS, Misbach J. Epidemiology of stroke in Indonesia: a systematic review. Cerebrovasc Dis. 2009;27:106.

8. World Health Organization. Global health observaroty data, Indonesia country profile 2015 [updated January 2015; cited 2015 March 26]. Available from: http://www.who.int/gho/ countries/idn/country_profiles/en/.

9. Ng N, Stenlund H, Bonita R, Hakimi M, Wall S, Weinehall L. Preventable risk factors for noncommunicable diseases in rural Indonesia: prevalence study using WHO STEPS approach. Bull World Health Organ. 2006;84:305-13.

10. Ahmed SM, Hadi A, Razzaque A, Ashraf A, Juvekar S, Ng N, et al. Clustering of chronic non-communicable disease risk factors among selected Asian populations: levels and determinants. Glob Health Action. 2009;2.

11. Ng N, Van Minh H, Tesfaye F, Bonita R, Byass P, Stenlund H, et al. Combining risk factors and demographic surveillance: potentials of WHO STEPS and INDEPTH methodologies for assessing epidemiological transition. Scand J Public Health. 2006;34:199-208.

12. Dans A, Ng N, Varghese C, Tai ES, Firestone R, Bonita R. The rise of chronic non-communicable diseases in southeast Asia: time for action. Lancet. 2011;377:680-9.

13. The National Institute of Health Research and Development. Ministry of Health. Republic of Indonesia. Result of National Basic Health Research (RISKESDAS 2007). 2008.

14. Danaei G, Finucane MM, Lin JK, Singh GM, Paciorek CJ, Cowan MJ, et al. National, regional, and global trends in systolic blood pressure since 1980: systematic analysis of health examination surveys and epidemiological studies with 786 countryyears and 5.4 million participants. Lancet. 2011;377:568-77.

15. Finucane MM, Stevens GA, Cowan MJ, Danaei G, Lin JK, Paciorek CJ, et al. National, regional, and global trends in bodymass index since 1980: systematic analysis of health examination surveys and epidemiological studies with 960 country-years and 9·1 million participants. Lancet. 2011;377:557-67.

16. Farzadfar F, Finucane MM, Danaei G, Pelizzari PM, Cowan MJ, Paciorek CJ, et al. National, regional, and global trends in serum total cholesterol since 1980: systematic analysis of health examination surveys and epidemiological studies with 321 country-years and 3.0 million participants. Lancet. 2011;377: 578-86.

17. Danaei G, Finucane MM, Lu Y, Singh GM, Cowan MJ, 
Paciorek CJ, et al. National, regional, and global trends in fasting plasma glucose and diabetes prevalence since 1980: systematic analysis of health examination surveys and epidemiological studies with 370 country-years and $2 \cdot 7$ million participants. Lancet. 2011;378:31-40.

18. Ministry of Health, Republic of Indonesia. Report of national basic health research (Riskesdas 2013). Jakarta, Indonesia: 2013 Available from: http://www.litbang.depkes.go.id/riskesnas.

19. Chobanian AV, Bakris GL, Black HR, Cushman WC, Green LA, Izzo JL Jr, et al. The Seventh Report of the Joint National Committee on Prevention, Detection, Evaluation, and Treatment of High Blood Pressure: the JNC 7 report. JAMA. 2003;289: 2560-72.

20. Indonesian Society of Endocrinology. Konsensus Pengendalian dan Pencegahan Diabetes Mellitus Tipe2 di Indonesia 2011. Jakarta: Indonesian Society of Endocrinology.

21. American Diabetes Association. Standards of medical care in diabetes-2011. Diabetes Care. 2011;34 Suppl 1:S11-61.

22. National Cholesterol Education Program (NCEP) Expert Panel on Detection, Evaluation, and Treatment of High Blood Cholesterol in Adults (Adult Treatment Panel III). Third Report of the National Cholesterol Education Program (NCEP) Expert Panel on Detection, Evaluation, and Treatment of High Blood Cholesterol in Adults (Adult Treatment Panel III) final report. Circulation. 2002;106(25):3143-421.

23. Woodward M, Barzi F, Martiniuk A, Fang X, Gu DF, Imai Y, et al. Cohort profile: the Asia Pacific Cohort Studies Collaboration. Int J Epidemiol. 2006;35:1412-6.

24. Levin ML. The occurrence of lung cancer in man. Acta Unio Int Contra Cancrum. 1953;9:531-41.

25. Daly LE. Confidence Limits Made Easy: Interval Estimation Using a Substitution Method. Am J Epidemiol. 1998;147: 783-90.

26. Preacher KJ, Selig JP. Advantages of Monte Carlo Confidence Intervals for Indirect Effects. Commun Methods Meas. 2012;6: 77-98.

27. EpiGear. Esartz workshop version. Brisbane: EpiGear International PTY LTD. 2010.

28. World Health Organization. WHO global report on trends in prevalence of tobacco smoking, 2015. Geneva: 2015.

29. Huxley RR, Hirakawa Y, Hussain MA, Aekplakorn W, Wang X, Peters SA, et al. Age- and Sex-Specific Burden of Cardiovascular Disease Attributable to 5 Major and Modifiable Risk Factors in 10 Asian Countries of the Western Pacific Region. Circ J. 2015;79:1662-74.

30. Huxley R, Barzi F, Woodward M. Excess risk of fatal coronary heart disease associated with diabetes in men and women: metaanalysis of 37 prospective cohort studies. BMJ. 2006;332:73-8.

31. Peters SA, Huxley RR, Woodward M. Diabetes as a risk factor for stroke in women compared with men: a systematic review and meta-analysis of 64 cohorts, including 775385 individuals and 12539 strokes. Lancet. 2014;383(9933):1973-80.

32. Ezzati M, Lopez AD, Rodgers A, Vander Hoorn S, Murray CJ;
Comparative Risk Assessment Collaborating Group. Selected major risk factors and global and regional burden of disease. Lancet. 2002;360(9343):1347-60.

33. Yusuf S, Hawken S, Ounpuu S, Dans T, Avezum A, Lanas F, et al. Effect of potentially modifiable risk factors associated with myocardial infarction in 52 countries (the INTERHEART study): case-control study. Lancet. 2004;364:937-52.

34. O’Donnell MJ, Xavier D, Liu L, Zhang H, Chin SL, RaoMelacini $\mathrm{P}$, et al. Risk factors for ischaemic and intracerebral haemorrhagic stroke in 22 countries (the INTERSTROKE study): a case-control study. Lancet. 2010;376:112-23.

35. Chang M, Hahn RA, Teutsch SM, Hutwagner LC. Multiple risk factors and population attributable risk for ischemic heart disease mortality in the United States, 1971-1992. J Clin Epidemiol. 2001;54:634-44.

36. Ezzati M, Hoorn SV, Lopez AD, Danaei G, Rodgers A, Mathers $\mathrm{CD}$, et al. Comparative Quantification of Mortality and Burden of Disease Attributable to Selected Risk Factors. In: Lopez AD MC, Ezzati M, et al, editor. Global Burden of Disease and Risk Factors. Washington (DC): World Bank; 2006.

37. Soemantri S, Pradono J, Hapsari D. SURKESNAS 2001. National Household Health Survey Morbidity Study-NCD Risk Factors in Indonesia.

38. Tesfaye F, Nawi NG, Van Minh H, Byass P, Berhane Y, Bonita $\mathrm{R}$, et al. Association between body mass index and blood pressure across three populations in Africa and Asia. J Hum Hypertens. 2007;21:28-37.

39. Soebardi S, Purnamasari D, Oemardi M, Soewondo P, Waspadji $\mathrm{S}$, Soegondo S. Dyslipidemia in newly diagnosed diabetes mellitus: the Jakarta primary non-communicable disease risk factors surveillance 2006. Acta Med Indones. 2009;41:186-90.

40. Zhang X, Patel A, Horibe H, Wu Z, Barzi F, Rodgers A, et al. Cholesterol, coronary heart disease, and stroke in the Asia Pacific region. Int J Epidemiol. 2003;32:563-72.

41. Martiniuk AL, Lee CM, Lawes CM, Ueshima H, Suh I, Lam TH, et al. Hypertension: its prevalence and population-attributable fraction for mortality from cardiovascular disease in the AsiaPacific region. J Hypertens. 2007;25:73-9.

42. Miettinen OS. Proportion of disease caused or prevented by a given exposure, trait or intervention. Am J Epidemiol. 1974;99: 325-32.

43. Rockhill B, Newman B, Weinberg C. Use and misuse of population attributable fractions. Am J Public Health. 1998;88: 15-9.

44. Benichou J. A review of adjusted estimators of attributable risk. Stat Methods Med Res. 2001;10:195-216.

45. Laaksonen M. Population Attributable Fraction (PAF) in epidemiologic followup studies. Helsinki, Finland; 2010.

46. Global status report on noncommunicable diseases 2014. Geneva, Switzerland: World Health Organization; 2014.

47. Maharani A, Tampubolon G. Unmet needs for cardiovascular care in Indonesia. PLoS One. 2014;9:e105831. 